\title{
Schizosaccharomyces pombe is More Sensitive to Pressure Stress than Saccharomyces cerevisiae
}

\author{
Mamiko Sato ${ }^{1}$, Hiromi Kobori², Sanae A. Ishijima ${ }^{1}$, Zha Hai Feng ${ }^{2}$, Kazuhiro Hamada ${ }^{3}$, Shoji \\ Shimada ${ }^{4}$, and Masako Osumi ${ }^{2 *}$ \\ ${ }^{1}$ Laboratory of Electron Microscopy, ${ }^{2}$ Department of Chemical and Biological Sciences, Faculty of Science, \\ Japan Women's University, Mejirodai, Bunkyo-ku, Tokyo, Japan, ${ }^{3}$ Fermentation and Food Research Labora- \\ tories, Oriental Yeast Co., Ltd., Azusawa, Itabashi-ku, Tokyo, Japan, ${ }^{4}$ Planning and Research Division, Orien- \\ tal Yeast Co., Ltd., Nihonbashi Honcho, Chuo-ku, Tokyo, Japan
}

Key words: hydrostatic pressure/Schizosaccharomyces pombe/microtubules/microfilaments/fluorescence microscopy/ immunoelectron microscopy

\begin{abstract}
The effects of hydrostatic pressure on ultrastructure, microtubules and microfilaments of Schizosaccharomyces pombe were investigated by fluorescence microscopy, conventional electron microscopy and immunoelectron microscopy. Cells were treated with hydrostatic pressure from 0.1 to $400 \mathrm{MPa}$ for $10 \mathrm{~min}$ at room temperature. The nuclear membrane was disrupted at above 100 MPa. At 150 MPa the matrixes of mitochondria had an electron dense area. At $250 \mathrm{MPa}$ the cytoplasmic substances changed dramatically, the cellular organelles could hardly be detected and the fragmented nuclear membrane was barely visible. The fluorescence in $\alpha$-tubulin was lost in most of the cells at $100 \mathrm{MPa}$. The gold particles for anti $\alpha$-tubulin were not visible in the cells at the same level. Cell cycle specific actin distribution was lost even at $50 \mathrm{MPa}$, although actin dots localized at the central region remained unchanged. Thick actin cables appeared at $100 \mathrm{MPa}$. Complete depolymerization of F-actin was observed at $150 \mathrm{MPa}$. These results suggest that $S$. pombe cells were more sensitive than Saccharomyces cerevisiae cells. The damage to microtubules and nuclear membrane caused by hydrostatic pressure was thought to be followed by breakdown of nuclear division apparatus and the inhibition of nuclear division. This damage might contribute to the frequent formation of polyploidy in $S$. pombe.
\end{abstract}

Our previous investigations by conventional electron microscopy related to hydrostatic pressure effects on the budding yeast Saccharomyces cerevisiae (16) and the dimorphic yeast $C$ Candida tropicalis $(14,15)$ revealed that the membrane systems, especially the nuclear membrane were most susceptible to pressure stress even at $100 \mathrm{MPa}$. An electron dense matrix appeared in the organelles and cytoplasm above $200 \mathrm{MPa}$. Under fluorescence microscopy cell cycle specific organization of microfilaments and microtubules was altered when $S$. cerevisiae and both yeast and hyphal form cells in C. tropicalis were exposed to hydrostatic pressure stress at 100 $150 \mathrm{MPa}$. Hyphal cells were found to be more sensitive to pressure treatment than yeast form cells and microtubules to be more sensitive than microfilaments (14).

It was also demonstrated that hydrostatic pressure of 200 to $250 \mathrm{MPa}$ greatly inactivated $S$. cerevisiae cells while inducing polyploidy at a high frequency of $15 \%$

\footnotetext{
* To whom corespondence should be addressed. Tel./Fax: 03-3942-6188.

Abbreviations: electron microscopy, EM; potassium phosphate, $\mathrm{KP}$; phosphate-buffered saline, PBS; bovine serum albumin, BSA
}

(6).

Immunoelectron microscopy (immuno EM) using ultrathin frozen sectioning (9) in $S$. cerevisiae revealed deposits of gold particles for anti $\alpha$-tubulin in the nucleus at $150 \mathrm{MPa}$, although no filamentous structure of microtubules was recognized. The damage to microtubules and nuclear membrane caused by such stress was thought to be followed by a breakdown of nuclear division apparatus and the inhibition of nuclear division. Onozato confirmed that the breakdown of the mitotic spindle after application of hydrostatic pressure induced the formation of polyploidy in salmonid eggs (13).

We recently found that polyploid cells of the fission yeast Schizosaccharomyces pombe were induced under lower pressure stress than those of $S$. cerevisiae and that polyploid cells were formed more frequently in $S$. pombe than in S. cerevisiae (5). Since the effect of pressure stress on ultrastructure and cytoskeletal elements in $S$. pombe has not been reported, we used fluorescence microscopy, conventional EM and immuno EM in this study to characterize this stress on $S$. pombe cells. We also focused on the effect of pressure on micro- 
tubules in order to determine whether there is a close relationship between breakdown of microtubules and polyploid formation in $S$. pombe.

We report here that the effect of pressure stress on the viability, ultrastructure and cytoskeleton of $S$. pombe cells was comparable to that in $S$. cerevisiae cells. $S$. pombe cells also were affected in most of the same subcellular structures, but more sensitively than budding yeasts. The involvement of microtubules in induction of polyploidy in $S$. pombe was suggested.

\section{MATERIALS AND METHODS}

Yeast strain and cultivation. The strain of S. pombe used in this work was L972 $h^{-}$. Stock cultures were maintained on an agar slant of YPD medium (1\% yeast extract, $2 \%$ polypeptone, and $2 \%$ glucose). The cells were aerobically grown at $30^{\circ} \mathrm{C}$ in YPD liquid medium to mid-exponential phase.

Pressure treatments. Cells suspended (approx. $10^{9}$ cells $/ \mathrm{ml}$ ) in fresh YPD liquid medium were put in small polyethylene bottles and placed in a high pressure apparatus, NKK-ABB or KP5B (6). Samples were treated with hydrostatic pressure of $0.1,30,50,100,150,200$ and $250 \mathrm{MPa}$ for $10 \mathrm{~min}$ at room temperature. The system of increasing pressure, maintaining it and decompression was automatic. The times required up to $250 \mathrm{MPa}$ and down to $0.1 \mathrm{MPa}$ were about $28 \mathrm{~s}$ and about 10 $\mathrm{s}$, using the automatic apparatus (6). The decompressed samples were immediately fixed to prepare specimens for fluorescence microscopy and EM as described below.

Colony-forming ability. The colony-forming ability of pressurized cells was determined by spreading the cell suspension on YPD agar plates, and the number of colonies appearing on the plates was counted after 3 days of incubation at $30^{\circ} \mathrm{C}(6)$.

Fluorescence microscopy. Fluorescent staining of microfilaments and microtubules in the pressurized and non-pressurized cells was accomplished by the following protocol. Since centrifugation alone was observed to alter the distribution of microfilaments in the cells, cell suspension was fixed with a concentrated formaldehyde solution in potassium phosphate buffer (KP buffer) added directly to the culture medium; the final concentrations were $3.7 \%(\mathrm{wt} / \mathrm{vol})$ formaldehyde and $50 \mathrm{mM} \mathrm{KP}$ buffer (pH 6.5). Microfilaments were visualized by staining the $\mathrm{F}$-actin of the cells with $0.3 \mu \mathrm{M}$ rhodamine-conjugated phalloidin as described (10).

Microtubules were visualized by indirect immunofluorescence. The fixed cells were washed three times with phosphatebuffered saline (50 mM PBS: $50 \mathrm{mM}$ KP buffer, pH 7.3, 150 $\mathrm{mM} \mathrm{NaCl}$ ) and treated with $0.5 \%$ of $\beta$-mercaptoethanol containing $50 \mathrm{mM}$ PBS for $30 \mathrm{~s}$. The cell walls were partially digested by adding Novozym $234(2.5 \sim 5.0 \mathrm{mg} / \mathrm{ml}$ in $50 \mathrm{mM}$ PBS, Novo Nordish a/s, Bagsvaerd, Denmark), and the cells were then incubated on a reciprocal shaker $(60 \mathrm{revs} / \mathrm{min})$ at $30^{\circ} \mathrm{C}$ for $8-13 \mathrm{~min}$. After being washed twice with $10 \mathrm{mM}$ PBS (10 mM KP buffer, pH 7.3, $150 \mathrm{mM} \mathrm{NaCl})$ the cells were permeabilized in suspension by $1 \%$ Triton X-100 in $10 \mathrm{mM}$
PBS for $30 \mathrm{~min}$. Following two washes with $10 \mathrm{mM}$ PBS, the pellet of cells was resuspended and incubated for $3 \mathrm{~h}$ in two volumes of $10 \%$ monoclonal rat anti-yeast $\alpha$-tubulin antibody (YL 1/2, Harlan, Ltd., Sera-Lab., Sussex, UK) containing $1 \%$ bovine serum albumin (BSA), $0.1 \%$ Triton X-100 and 10 mM PBS. Cells were washed with $10 \mathrm{mM}$ PBS, then treated with $6.7 \%$ affinity purified FITC goat anti-rat IgG (Organon Teknika Corp., Cappel ${ }^{\mathrm{TM}}$ Research Products, Durham, NC, USA) and $10 \mathrm{mM}$ PBS for $1 \mathrm{~h}$. The stained cells were viewed through a fluorescence microscope as described (8) except that the instrument used was an Olympus BX-FLA.

Preparation for conventional electron microscopy. Cell suspensions were fixed with $2.5 \%(\mathrm{w} / \mathrm{v})$ glutaraldehyde in $0.1 \mathrm{M}$ phosphate buffer, $\mathrm{pH} 7.2$, for $2 \mathrm{~h}$ at $4^{\circ} \mathrm{C}$. Cells were washed with $0.1 \mathrm{M}$ phosphate buffer, postfixed with $1.5 \%$ $\mathrm{KMnO}_{4}$ in distilled water for $17 \mathrm{~h}$ at $4^{\circ} \mathrm{C}$, block stained with $0.5 \%(\mathrm{w} / \mathrm{v})$ uranyl acetate in distilled water for $1 \mathrm{~h}$ at $4^{\circ} \mathrm{C}$ and embedded in agar blocks. Dehydration was done by alcohol series and absolute acetone; cells were embedded in Quetol 653. Ultrathin sections were stained with uranyl acetate and lead citrate and examined with a JEM 1200 EXS electron microscope at $120 \mathrm{kV}$ (14).

Immunoelectron microscopy by frozen thin sectioning. After pressure treatment, cell suspensions were fixed with a mixture of $0.5 \%$ glutaraldehyde and 3\% paraformaldehyde for $1 \mathrm{~h}$ at room temperature. Cells were treated with $1 \%$ sodium metaperiodate for $15 \mathrm{~min}$ and $50 \mathrm{mM}$ ammonium chloride for $30 \mathrm{~min}$ at room temperature, and then washed with 50 $\mathrm{mM}$ Tris-buffered saline (TBS: $50 \mathrm{mM}$ Tris- $\mathrm{HCl}$ buffer, $\mathrm{pH}$ $7.5,0.8 \% \mathrm{NaCl})$. The cells were mounted with $2 \%$ agarose, infused with a $20 \%$ polyvinyl pyrrolidone $/ 1.84 \mathrm{M}$ sucrose mixture in $0.1 \mathrm{M}$ PBS, then frozen with propane, and sectioned by Reichelt FCS (Lica Austria) at $-100^{\circ} \mathrm{C}$. To visualize microtubules, sections were first incubated with $1.5 \%$ normal goat IgG in $0.1 \% \mathrm{BSA} / \mathrm{TBS}$ for $30 \mathrm{~min}$, and then placed directly on rat monoclonal anti-yeast $\alpha$-tubulin antibody (YOL 1/34, Sera-Lab., Sussex, UK, 1:10 dilution) in 0.1\% BSA/TBS for $16 \mathrm{~h}$. They were then placed on a drop of goat anti-rat IgG conjugated to $10 \mathrm{~nm}$ colloidal gold (Amersham International plc, 1:40 dilution) for $2 \mathrm{~h}(9)$. The same procedure used to visualize microtubules was employed to visualize microfilaments, except that rabbit monoclonal anti-chicken gizzard actin antibody (Transformation Research Inc. Framingham, MA USA, $1: 60$ dilution) and goat anti-rabbit IgG conjugated to $10 \mathrm{~nm}$ colloidal gold (British BioCell International Technical Services Department, 1:40 dilution) were used for detection of Factin. Sections were stained with 3\% uranyl acetate for 10 $\mathrm{min}$, and adsorption-stained with a $0.3 \%$ uranyl acetate $/ 3 \%$ polyvinyl alcohol mixture for over $5 \mathrm{~min}$. All these procedures were done at room temperature. The sections were examined with a JEM 1200 EXS TEM (JEOL) at $120 \mathrm{kV}$.

\section{RESULTS AND DISCUSSION}

Response of S. pombe cells to pressure stress. The 
survival curves of $S$. pombe and $S$. cerevisiae cells depending on colony-forming ability are shown in Fig. 1. Above $100 \mathrm{MPa} S$. pombe cells displayed a drastic decrease in proliferation and at pressures over $200 \mathrm{MPa}$ (-) were almost completely inactivated. In S. cerevisiae, however, this ability was sharply reduced with increasing pressure when the pressure stress exceeded 150 $\mathrm{MPa}(-)$; above $250 \mathrm{MPa}$ the cells lost all ability to proliferate. Thus $S$. pombe cells were more sensitive to pressure stress than $S$. cerevisiae cells (5).

Transmission electron microscopic images of the ultrastructure of pressure stressed cells by conventional thin sectioning. Figure 2 shows a potassium permanganate fixed cell. The normal ultrastructure of organelles - nucleus, mitochondria and vacuoles - is seen in non-treated cells by pressure stress (Fig. 2a). After treatment at $100 \mathrm{MPa}$, however, the nuclear membrane was damaged and fragmented (Fig. 2b, $\leftarrow$ ); this strongly damaged profile was the most severe of all yeasts we observed $(14,15,16)$. At $150 \mathrm{MPa}$ another altered feature was apparent - the matrixes of the mitochondria had an electron dense area (Fig. 2c, $\leftarrow$ ). At above $250 \mathrm{MPa}$ the cytoplasmic substance changed dramatically (Fig. $2 \mathrm{~d}$ ), which was not recognized in other yeast cells fixed with potassium permanganate; the cellular organelles could hardly be detected and the fragmented nuclear membrane was barely visible. This damaged profile was similar to other yeast cells, but $S$. pombe cells were more affected at low pressure stress than were $S$. cerevisiae cells.

It is noteworthy that similar electron dense areas were detected in the mitochondrial matrixes of $S$. pombe cells $(150 \mathrm{MPa})$ when the $S$. cerevisiae cells were exposed to pressure stress (9), heat stress, ethanol, or hydrogen peroxide stress (17). This indicates that change

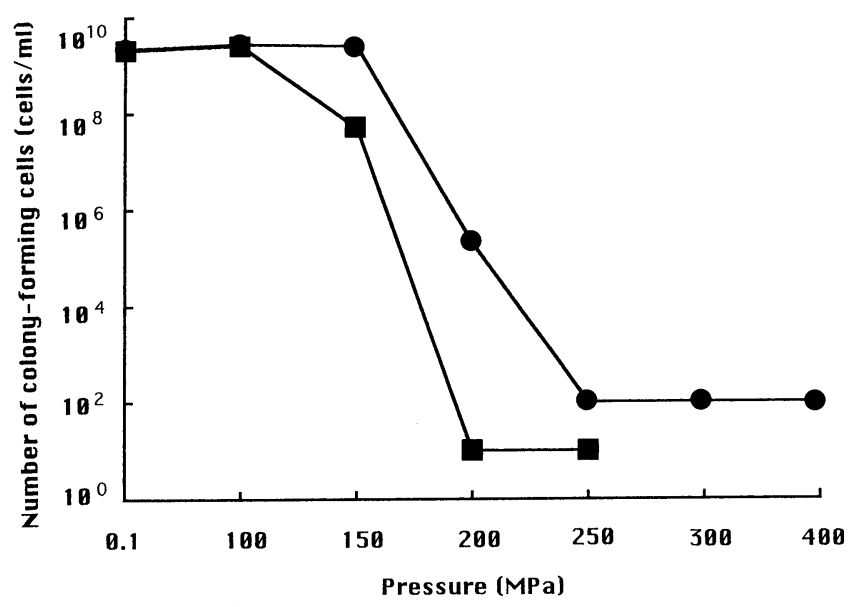

Fig. 1. Effect of hydrostatic pressure stress on colony-forming ability of $S$. pombe and $S$. cerevisiae. Results shown here are typical of those from three experiments. - , S. pombe - - S. cerevisiae. induced by pressure stress and other types of stress results in a similar phenomenon at the ultrastructural level.

Effects of pressure on microtubules in fission yeast cells. Figure 3 shows the effects of pressure on microtubules in yeast cells by fluorescence microscopy. The organization of microtubules visualized in the cells without pressure treatment $(0.1 \mathrm{MPa})$ was the same as that reported in $S$. pombe L972 $h^{-}$by Hagan and Hyams (4). During interphase groups of cytoplasmic microtubules extended between the two ends of the cells (Fig. $3 \mathrm{a}, \leftarrow(1)$ ). As the cell entered mitosis these cytoplasmic microtubules disappeared and were replaced by intranuclear spindle microtubules. Cells in early metaphase showed short spindle microtubules (Fig. 3a, Ł(2) and in late metaphase long profile (Fig. 3a, $\leftarrow$ (3)); the distribution of microtubules was not altered at $50 \mathrm{MPa}$ (Fig. $3 b$ ). At $100 \mathrm{MPa}$ disrupted spindle microtubules (Fig. $3 \mathrm{c}, \leftarrow$ ) and cytoplasmic microtubules (Fig. 3c, $\leftleftarrows$ ) were observed in a few percent of the total cells examined, however, the fluorescence in $\alpha$-tubulin was lost in most of the cells at this level (Fig. 3d).

Fluorescence microscopic observation of $S$. cerevisiae showed the organization of microtubules to be slightly altered and spindle microtubules to be partially disrupted at $150 \mathrm{MPa}$. At $200 \mathrm{MPa}$ both cytoplasmic and spindle microtubules were fragmented and at 250 and $300 \mathrm{MPa}$ no fluorescence of tubulin was observed (14).

The morphological consequences to microtubules in pressure-stressed cells were studied in more detail by immuno EM. Although the microtubules were barely discernible $\left(\leftarrow\right.$ ) in the nucleus (Fig. $4 \mathrm{a}_{1}$ ), most of the gold particles for anti $\alpha$-tubulin were visible in the nucleus in the cells without pressure treatment. The cells without deposits of colloidal gold particles in the nucleus had microtubules only in cytoplasm (Fig. $4 \mathrm{a}_{2}, \leftarrow$ ).

Spindle and cytoplasmic microtubules were never seen together in the same cell processed by frozen thin section; this agreed with the data of fluorescence microscopy (Fig. 3) (4). Morphological characteristics of microtubules and deposits of colloidal gold particles $(\leftarrow)$ for anti $\alpha$-tubulin were not affected when cells were treated below $50 \mathrm{MPa}$ (Fig. 4b). At $100 \mathrm{MPa}$ the two types of microtubules were hardly visible. Only a few percent of the cells showed an abnormal appearance of $\alpha$-tubulin localization (Fig. 4c, $\leftarrow$ ) and most displayed no gold particles.

Effects of pressure on microfilaments in yeast cells. Figure 5 shows the effects of pressure on microfilament in yeast cells as revealed by fluorescence microscopy (Figs. 5a, b, c) and immuno EM (Fig. 5d). The organization of microfilaments visualized in the cells without pressure treatment $(0.1 \mathrm{MPa})$ was the same as that reported in S. pombe L $972 h^{-}$by Marks and Hyams (11). The distribution of actin was divided into three distinct 


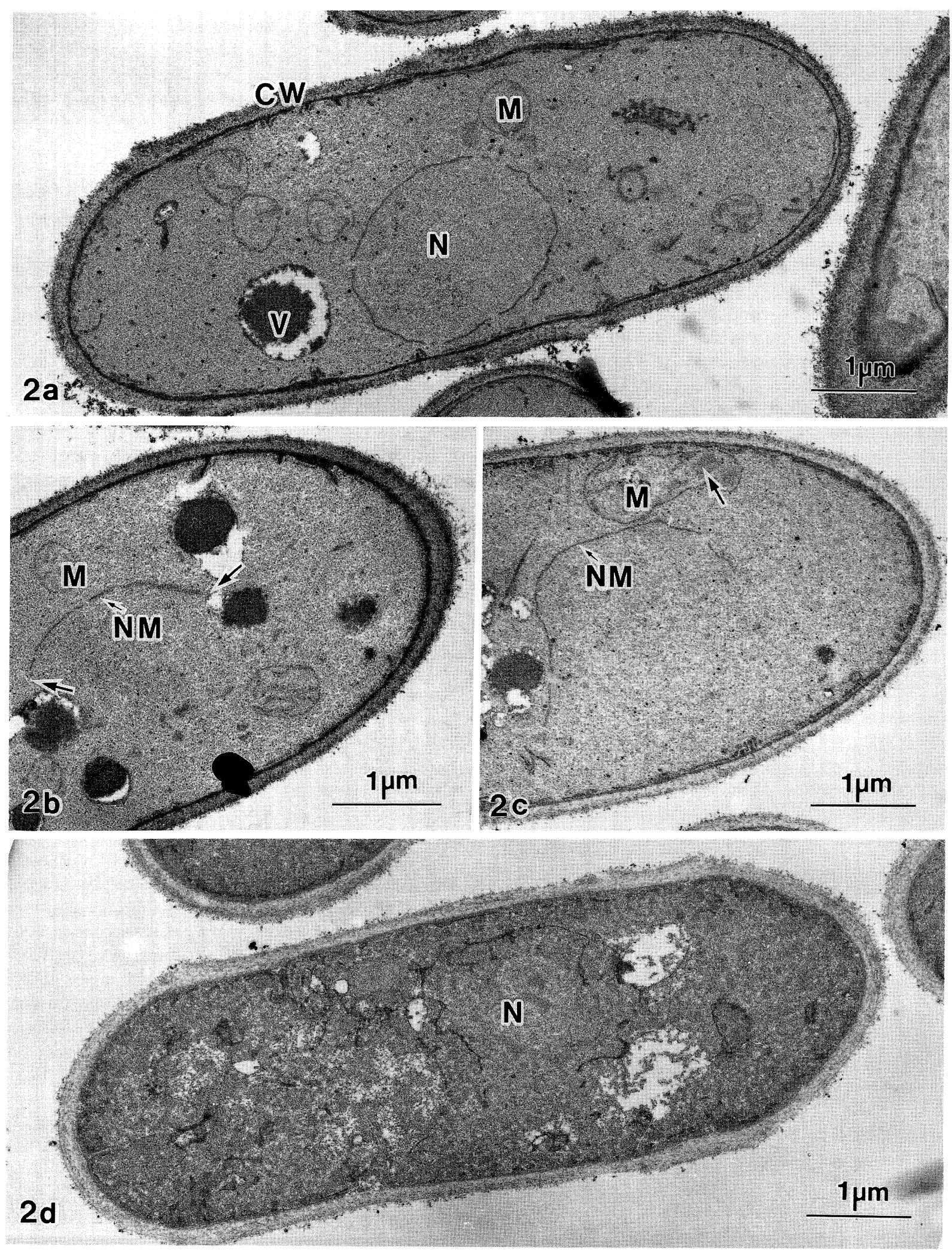

Fig. 2. Transmission electron microscopic images of $S$. pombe treated without (a) and with hydrostatic pressure of 100 (b), 150 (c) and 250 (d) $\mathrm{MPa}$. $\mathrm{CW}$, cell wall; $\mathrm{M}$, mitochondria; N, nucleus; NM, nucleus membrane; $\mathrm{V}$, vacuole. 

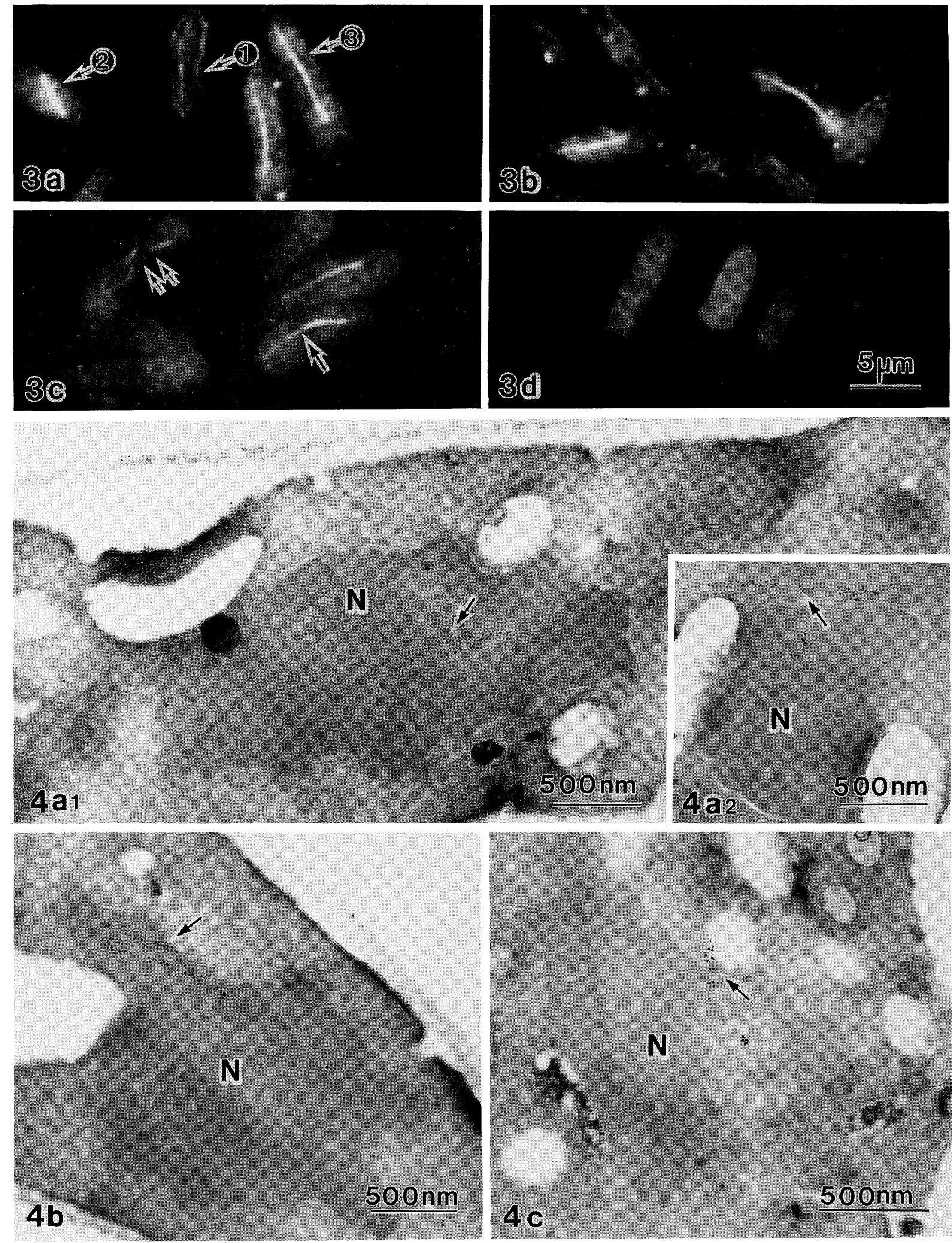

Fig. 3. Fluorescence microscopic images of microtubules of $S$. pombe cells treated without (a) and with pressure of 50 (b), 100 (c, d) MPa.

Fig. 4. Immuno EM images of frozen sections of $S$. pombe treated without (a) and with pressure of 50 (b) and 100 (c) MPa. N, nucleus. 
stages during the cell cycle. At the beginning of the cycle all of the actin dots were present at one end (the old end) of the cell (Fig. 5a, $\leftarrow$ (1)). In the bidirectional growth phase, actin dots existed at both ends (Fig. 5a, $\leftarrow$ (2). The third stage was a post-mitotic stage, where actin dots were concentrated in the central region, followed by septum formation and cytokinesis (Fig. 5a, $\leftarrow$ (3). When the cells were pressurized for $10 \mathrm{~min}$, cell cycle specific actin distribution was lost even at $50 \mathrm{MPa}$, although actin patches in the central region remained unchanged (Fig. 5b, $\leftarrow$ ). Thick actin cables appeared at $100 \mathrm{MPa}$ (Fig. 5c).

The drastic morphological changes of microfilaments induced at $100 \mathrm{MPa}$ were also observed by immuno EM using frozen thin section. Concentrated colloidal gold particles shown by the arrows in Fig. 5d apparently corresponded to the thick actin cables shown in Fig. 5c. Complete depolymerization of F-actin was observed at $150 \mathrm{MPa}$ (data not shown).

Table I summarizes the effects of hydrostatic pressure on microtubules, microfilaments, ultrastructure and colony-forming ability of $S$. pombe cells. Corresponding results of $S$. cerevisiae cells are also shown. Fluores- cence microscopy revealed that both microtubules and microfilaments of $S$. pombe were more susceptible to pressure than those of $S$. cerevisiae. Electron microscopic observation of ultrastructure and microtubules also indicated that $S$. pombe cells were damaged more severely than $S$. cerevisiae.

Colony-forming ability of $S$. pombe was lost at lower pressure stress than that of S. cerevisiae.

All characteristics listed in Table I show that $S$. pombe is more pressure-susceptive than S. cerevisiae. This susceptibility would stem from that of microtubules and nuclear membrane of $S$. pombe to pressure stress, because the damage to these features caused by pressure stress induced inhibition of the nuclear division in $S$. pombe: the major components of the nuclear division apparatus such as spindle microtubules were severely damaged. It is well known that the nuclear membrane does not break down during nuclear division in yeast (1); it is therefore closely involved in the elongation of the spindle in this organism during mitosis. Thus damage to both microtubules and nuclear membrane would affect mitosis, making the cells incapable of growth.
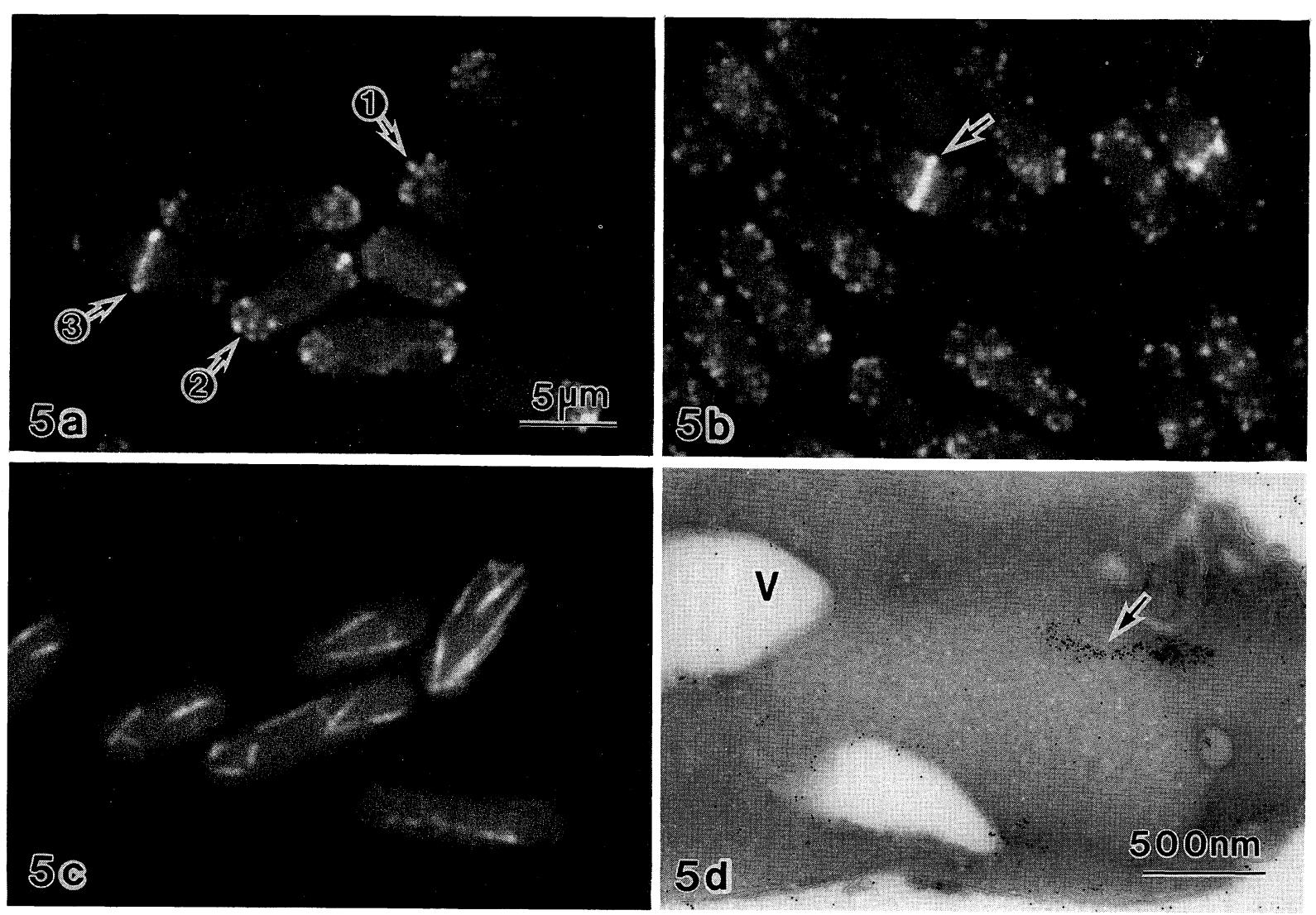

Fig. 5. Changes of microfilaments by hydrostatic pressure in $S$. pombe cells. Images of fluorescence microscopy without (a) and with pressure of 50 (b), and 100 (c) $\mathrm{MPa}$ and those of immuno EM with pressure of 100 (d) MPa. V, vacuole. 
Table I. Comparison of Effects of Pressure between S. CEREVISIAE and S. POMBE

\begin{tabular}{lllcc}
\hline \multirow{2}{*}{ Method } & \multirow{2}{*}{ Characteristic } & \multirow{2}{*}{ Remarks } & \multicolumn{2}{c}{ Minimum pressure (MPa) } \\
\cline { 3 - 5 } Fluorescence microscopy & Microtubules & abnormal distribution & S. pombe & S. cerevisiae \\
& & disappearance & 100 & 150 \\
& Ultrastructure & nuclear membrane altered & 100 & 250 \\
\hline \multirow{2}{*}{ Electron microscopy } & & dense matrix in mitochondrion & 150 & 150 \\
& Microtubules & disappearance of immuno gold particles & 100 & 200 \\
& Microfilaments & abnormal distribution & 50 & 150 \\
\hline Fluorescence microscopy & & disappearance & 150 & 150 \\
\hline Plate counting & Colony-forming ability & complete loss & 200 & 250 \\
\hline
\end{tabular}

Damage and disappearance of spindle microtubules induced by pressure stress in $S$. pombe would also lead to the induction of polyploidy; such induction has been reported in many higher eukaryotes after treatment of hydrostatic pressure $(3,13)$. Onozato $(13)$ demonstrated that severe damage of spindle microtubules by pressure stress resulted in the induction of polyploidy in salmonid eggs. A similar phenomenon occurred in S. pombe. We reported earlier that induction of polyploidy in $S$. cerevisiae is accompanied by the breakdown and reassembly of spindle microtubules (14). The induction of polyploid cells by pressure stress therefore, apparently occurs widely in yeasts and lower eukaryotes.

Similar successive changes in the patterns of microtubules and microfilaments accompanied by the acceleration of pressure stress were observed between $S$. pombe and $S$. cerevisiae (14). In microtubules cell cycle specific distribution was lost by the fragmentation of both cytoplasmic and spindle microtubules and these then disappeared. In microfilaments the cell cycle specific localization (14) of F-actin disappeared, actin dots were randomly distributed through the cytoplasm and then the actin cable appeared followed by the disappearance (disassembly) of F-actin in both yeasts.

Similar drastic changes in the distribution of microfilaments observed in this study have been reported in $S$. pombe when the cells were starved in distilled water (7); starvation for $1 \mathrm{~h}$ at $37^{\circ} \mathrm{C}$ resulted in the loss of cell cycle specific actin distribution and the even distribution of actin dots in the cytoplasm. After $4 \mathrm{~h}$ thick actin cables were seen running through the cytoplasm. It is interesting to note that there were similar changes between the acceleration of pressure and prolongation of starved conditions. At present it is not possible to explain the mechanism of changes in the pattern of F-actin; however, the interaction between actin and actin-binding proteins might affect the formation and maintenance of the structure of F-actin and its polymerization, as suggested in the studies on osmotic stress (2) and protein synthesis inhibitor in $S$. cerevisiae (12).
Acknowledgments. The authors thank Miss Masako Tanida and Miss Rena Kawai for technical assistance.

\section{REFERENCES}

1. Byers, B. 1981. Cytology of the yeast life cycle. In The Molecular Biology of the Yeast Saccharomyces (eds., J.N. Strathern, E.W. Jons and J.R. Broach), pp.1: 59-96. New York: Cold Spring Harbor Laboratory.

2. Chowdhury, S., Smith, K.W., and Gustin, M.C. 1992. Osmotic stress and the yeast cytoskeleton: Phenotype-specific suppression of an actin mutation. J. Cell Biol., 118: 561-571.

3. DASGUPTA, S. 1962 . Induction of triploidy by hydrostatic pressure in the leopard frog, Rana pipiens. J. Exp. Zool., 151: 105121.

4. Hagan, I.M. and Hyams, J.S. 1988. The use of cell division cycle mutants to investigate the control of microtubule distribution in the fission yeast Schizosaccharomyces pombe. J. Cell Sci., 89: 343-353.

5. Hamada, K., NaKatomi, Y., Osumi, M., and Shimada, S. 1996. Direct induction of homozygous diploidization in the fission yeast Schizosaccharomyces pombe by pressure stress. FEMS Microbiol. Lett., 136: 257-262.

6. Hamada, K., Nakatomi, Y., and Shimada, S. 1992. Direct induction of tetraploids or homozygous diploids in the industrial yeast Saccharomyces cerevisiae by hydrostatic pressure. Curr. Genet., 22: 371-376.

7. Kanbe, T., Tomohiro, A., and TanaKa, K. 1994. Changes in the distribution of F-actin in the fission yeast Schizosaccharomyces pombe by arresting growth in distilled water: Correlative studies with fluorescence and electron microscopy. J. Electron Microsc., 43: 20-24.

8. Koвori, H., Sato, M., and Osumi, M. 1992. Relationship of actin organization to growth in the two forms of the dimorphic yeast Candida tropicalis. Protoplasm, 167: 193-204.

9. Kobori, H., Sato, M., Tameike, A., Hamada, K., Shimada, S., and Osumi, M. 1995. Ultrastructural effects of pressure stress to nucleus in Saccharomyces cerevisiae: a study by immunoelectron microscopy using frozen thin sections. FEMS Microbiol. Lett., 132: 253-258.

10. Kobori, H., Yamada, N., TAKI, A., and Osumi, M. 1989. Actin is associated with the formation of the cell wall in reverting protoplasts of the fission yeast Schizosaccharomyces pombe. $J$. Cell Sci., 94: 635-646.

11. Marks, J. and Hyams, J.S. 1985. Localization of F-actin 
through the cell division cycle of Schizosaccharomyces pombe. Eur. J. Cell Biol., 39: 27-32.

12. Novick, P., Osmond, B.C., and Bostein, D. 1989. Suppressors of yeast actin mutations. Genetics, 121: 659-674.

13. Onozato, H. 1984. Diploidization of gynogenetically activated salmonid eggs using hydrostatic pressure. Aquaculture, 43: 91-97.

14. Osumi, M., Yamada, N., Sato, M., Kobori, H., Shimada, S., and HAYASHI, R. 1992. Pressure effects of yeast cell ultrastructure: change in the ultrastructure and cytoskeleton of the dimorphic yeast, Candida tropicalis. In High Pressure and Biotechnology. (eds., C. Balny, R. Hayashi, K. Heremans, and P. Masson). vol.224, pp.9-18. Colloque INSERM/John Libbey Eurotext, Ltd.
15. Sato, M., Kobori, H., Shimada, S., and Osumi, M. 1995. Pressure-stress effects on the ultrastructure of cells of the dimorphic yeast Candida tropicalis. FEMS Microbiol. Lett., 131: 11-15.

16. Shimada, S., Andou, M., Naito, N., Yamada, N., Osumi, M., and HAYASHI, R. 1993. Effects of hydrostatic pressure on the ultrastructure and leakage of internal substances in the yeast $\mathrm{Sac}$ charomyces cerevisiae. Appl. Microbiol. Biotechnol., 40: 123131.

17. WeBster, D.L. and WATSON, K. 1993. Ultrastructural changes in yeast following heat shock and recovery. Yeast, 9: 11651175 .

(Received for publication, February 13, 1996

and in revised form, March 14, 1996) 